rev.relac.int.estrateg.segur.8(1):279-308,2013

\title{
LA RELACIÓN ENTRE INTEGRACIÓN Y SEGURIDAD EN EL MERCOSUR $Y$ SUS PROYECCIONES HACIA SUDAMÉRICA*
}

\author{
Jorge Riquelme Rivera*
}

\section{RESUMEN}

El presente trabajo analiza la relación entre integración y seguridad en el MERCOSUR. Es decir, más allá de los aspectos económicos y comerciales que involucra esta instancia, el artículo se refiere a sus aportes políticos en el ámbito de la seguridad regional. Para tal efecto, se examinan los avances que ha implicado dicho proceso de integración para la seguridad en el Cono Sur, planteando que, como instancia estratégica, el MERCOSUR ha favorecido la seguridad y estabilidad en la subregión, teniendo importantes efectos de derrame a

* Este artículo forma parte de la investigación doctoral que el autor está actualmente realizando, en el marco del programa de Doctorado en Relaciones Internacionales de la Universidad Nacional de La Plata, Argentina, que lleva como título "Comunidades de Seguridad: la perspectiva de América del Sur".

** Licenciado y Profesor de Estado en Historia y Geografía, Universidad de Santiago de Chile. Licenciado en Ciencia Política, Pontificia Universidad Católica de Chile. Magíster en Estudios Internacionales, Universidad de Chile. Doctorando en Relaciones Internacionales, Universidad Nacional de La Plata. Estudios de especialización en la Academia Nacional de Estudios Políticos y Estratégicos (ANEPE) y en el Centro de Estudios Hemisféricos de Defensa, Washington D.C. Es analista político del Ministerio de Relaciones Exteriores de Chile y ejerce docencia en la Universidad de Chile. Este trabajo es de exclusiva responsabilidad del autor y no representa la opinión de la institución en la cual se desempeña.jriquelme@minrel.gov.cl 
nivel sudamericano, siendo la más reciente expresión de esta tendencia la constitución del Consejo de Defensa Suramericano. En esta línea, se sostiene que el MERCOSUR, desde sus inicios, impulsó una naciente comunidad de seguridad en el Cono Sur, que ha tendido a proyectarse a América del Sur en su conjunto.

Palabras Clave: Integración regional, liderazgo regional, comunidad de seguridad, MERCOSUR, UNASUR, Consejo de Defensa Suramericano

\title{
THE RELATION BETWEEN INTEGRATION AND SECURITY IN THE MERCOSUR AND ITS PROJECTIONS TOWARD SOUTH AMERICA
}

\begin{abstract}
This work analyzes the relation between integration and security in the MERCOSUR. That is, beyond the economic and commercial aspects that this stage entails, the article refers to its political contribution in the sphere of regional security. In this regard, an assessment is made of the progress that this type of integration process has meant for security in the Southern Cone, pointing out that, as an strategic instance, MERCOSUR has facilitated the security and stability in the sub-region, having an important "leak" effect at the South American level, being the most recent expression of this tendency the constitution of the South American Defense Council. It is discussed that MERCOSUR, from its origins, promoted a rising security community in the Southern Cone, which has had the tendency to project itself to South America as a whole.
\end{abstract}

Key Words: Regional integration, regional leadership, security community, MERCOSUR, UNASUR, South American Defense Council

\section{A RELAÇÃO ENTRE INTEGRAÇÃO E SEGURANÇA NO MERCOSUL E SUA PROJEÇÃO NA AMÉRICA DO SUL}

\section{RESUMO}

Este artigo analisa a relação entre integração e segurança no MERCOSUL. Quer dizer, além dos aspectos econômicos e comerciais que envolvem este caso, o artigo faz referencia às suas contribuições políticas em matéria de segurança regional. Para este fim, serão examinados os progressos que envolveram este processo de integração para a segurança no Cone Sul, afirmando que, como instância estratégica, o MERCOSUL favoreceu a segurança e a estabilidade na sub-região, com repercussões importantes de difusão na América do Sul, sendo que a mais recente manifestação desta tendência é a constituição do Conselho de Defesa Sul-Americano. Neste sentido, argumenta-se que o Mercosul, desde a sua criação, 
incentivou uma comunidade de segurança nascente no Cone Sul, com tendência a se projetar como um todo para a América do Sul.

Palavras-chave: integração regional, liderança regional, segurança da comunidade, MERCOSUL, UNASUL, Conselho de Defesa Sul-Americano

\section{INTRODUCCIÓN}

Durante los últimos años, diversas críticas se han lanzado sobre el Mercado Común del Sur (MERCOSUR) y las tendencias que se aprecian, a nivel general, en el proceso de integración en Sudamérica. Entre ellas se cuentan las diatribas de los socios menores del bloque, que cuestionan los reales beneficios de su pertenencia al proceso de integración, aduciendo que este no estaría respondiendo a sus intereses. Ilustradora resultó en tal sentido la frase pronunciada en julio de 2009 por el entonces candidato del Frente Amplio a la presidencia de Uruguay, José Mujica, quien sostuvo que el MERCOSUR "anda rengo y a la miseria". Entre otras, las dificultades del bloque se relacionan con la necesidad de reducir las asimetrías y disparidades entre los miembros, el proteccionismo, así como con la vulnerabilidad externa de algunos de ellos.

Destacan recientemente las pugnas suscitadas entre Brasil y Argentina por las medidas proteccionistas aplicadas por este último, que tuvieron como correlato la eliminación, por parte del primero, de las licencias anticipadas para ciertos productos -como manzanas, peras, uvas y vinos- importados desde el país del sur. A ello se suman las dificultades para lograr un acuerdo en las dilatadas negociaciones entre la Unión Europea y el MERCOSUR, que se han visto fuertemente afectadas por la decisión argentina de expropiar el 51\% de las acciones de la petrolera YPF, en manos de la empresa española Repsol.

Pero las dificultades del MERCOSUR son las dificultades que enfrenta la integración regional en su conjunto, donde predomina la falta de un liderazgo definido, el nacionalismo, la falta de consenso, y los discursos altisonantes de las autoridades políticas, que no van de la mano de los resultados esperados (Malamud, 2009). En Sudamérica, las características mismas de la integración son el reflejo de la fragmentación que es posible apreciar en la región. Actualmente se ensayan en América del Sur diversos procesos, los que exhiben notables elementos estratégicos y obedecen a objetivos e intereses diferentes y que, asimismo, han tenido resultados dispares, tales como la Comunidad Andina (CAN); el mencionado MERCOSUR; y más recientemente el caso de la Unión de Naciones Suramericanas (UNASUR), cuyo antecedente directo fue la Comunidad Sudamericana de Naciones (CSN). En tal sentido, no puede dejar de mencionarse, además, la Alianza Bolivariana para los Pueblos de Nuestra América (ALBA), impulsada por Venezuela.

En este complejo marco, con avances y retrocesos, la región intenta posicionarse en un escenario internacional que a paso creciente, aunque intermitentemente interrumpido por los cíclicos 
períodos de crisis, avanza hacia el multipolarismo. Según Fareed Zakaria (2009), en la actualidad se asiste a un gran cambio de poder en el mundo, que denomina "la emergencia del resto" (the rise of the rest). Esta vasta transformación se expresaría en la configuración de nuevos polos de poder político y económico en el orbe, siendo el caso más representativo el gran dinamismo que exhibe China, cuya presencia en América del Sur resulta determinante para gran parte de las economías de la región.

Según Zakaria, este renovado escenario contribuiría a crear un nuevo sistema internacional, en el cual países en variadas partes del mundo se estarían transformando ya no en meros espectadores, sino en actores protagonistas por pleno derecho. De este modo, se estaría en presencia de un nuevo escenario mundial, donde se desarrollan y surgen nuevos poderes, como Brasil, China, India y Sudáfrica (que junto a Rusia forman parte del denominado BRICS), los que apoyarían la configuración de un escenario crecientemente multipolar. Algunos analistas han llevado más allá esta reflexión, planteando que estaríamos en presencia del "Mundo de Nadie", una etapa de no-polaridad, donde ningún actor regional estaría en condiciones de asumirse como hegemón global.

Un ejemplo de la "emergencia del resto" es la pujanza de los países del BRICS, que según estimaciones de Goldman Sachs, combinando su Producto Interno Bruto (PIB), superarían el PIB combinado de los países del G-7 para el año 2035. Bajo el mismo prisma puede apreciarse el protagonismo que últimamente se observa en el terreno de la política multilateral por parte del G-20 que, agrupando a grandes potencias y potencias emergentes, ha llegado incluso a cuestionar el liderazgo de Naciones Unidas para la resolución de los grandes temas de la agenda económica global.

Este escenario internacional está marcado por una creciente descentralización del poder y por la relevancia que han ido adquiriendo las regiones para dotar de gobernanza al escenario internacional. En este marco, el incremento de las posibilidades de incidencia en las cuestiones globales y en la resolución de los asuntos regionales pasa, desde luego, por la capacidad de los países para superar la lógica de la fragmentación y la competencia, y avanzar por el camino de la integración.

Ciertamente, este escenario multipolar y descentralizado tiene características bastante distintas al que vio surgir al MERCOSUR en los albores de la década de los noventa, que coincidía con el contexto del fin de la Guerra Fría, la "resurrección" de las Naciones Unidas y la transitoria hegemonía estadounidense (Pinheiro, 2012:13). En ese entonces, luego de una compleja competencia estratégica entre Brasil y Argentina, comenzó a darse un acercamiento desde mediados de la década de los ochenta que derivó en el establecimiento del MERCOSUR en 1991, mediante el Tratado de Asunción. Según Gert Rosenthal (1993), la integración regional se desarrolló en la década de los noventa en el marco de tres nuevos rasgos: la creciente globalización 
de los fenómenos económicos, y, como respuesta a este fenómeno, una gradual tendencia hacia una mayor convergencia entre los países de la región en materia de política económica; por último, un creciente avance hacia regímenes plurales, participativos y democráticos. Ciertamente, las críticas al MERCOSUR provienen de un contexto internacional y regional distinto al que le dio origen, luego de la denominada década perdida de los ochenta.

Sobre esta base, el presente trabajo pretende analizar los aportes del MERCOSUR bajo el prisma de la relación entre integración y seguridad. Es decir, más allá de los aspectos económicos y comerciales que involucra este proceso de integración, este artículo se refiere a los aportes políticos de esta iniciativa para la seguridad regional. Teniendo en cuenta que las críticas al MERCOSUR tienen un carácter metodológico, apuntando a la necesidad de que éste "trabaje mejor", y no a un cuestionamiento a la existencia misma del bloque ${ }^{1}$, en este estudio se sostiene que, como instancia estratégica, el MERCOSUR ha favorecido la seguridad y estabilidad en el Cono Sur, teniendo importantes efectos de derrame a nivel sudamericano. En tal sentido, se plantea -desde la terminología de la teoría de la integración- que el MERCOSUR ha favorecido el desarrollo de una comunidad pluralista de seguridad en el Cono Sur, que ha tendido a proyectarse a nivel de América del Sur en su conjunto, siendo la más reciente expresión de este proceso el importante desarrollo que exhibe el Consejo de Defensa Suramericano, en el marco de la UNASUR.

\section{LA INTEGRACIÓN Y LA SEGURIDAD DESDE UNA PERSPECTIVA TEÓRICA}

En un nivel general, puede sostenerse que todo proceso de integración implica el avance hacia el establecimiento de decisiones colectivas, lo que involucra la reingeniería de las políticas de los países a las nuevas realidades de un contexto de construcción de una comunidad. Este sería el sentido de la integración, que se constituye como un proceso que intenta generar un todo con las partes, transformando unidades previamente separadas en componentes de un sistema coherente, cuya característica esencial en tanto sistema, es el grado significativo de interdependencia entre sus componentes.

1. El mismo José Mujica señaló en julio de 2009 que "Nosotros tenemos una dificultad tremenda de poder siquiera arrimarnos un poco. Me doy cuenta que para exigir algo en el mundo que viene tenemos que juntarnos con todos para tener cierto peso en el mundo, de lo contrario somos una hoja al viento...".

Véase URL: <http://www.ultimasnoticias.com.uy/hemeroteca/270709/prints/act06.html> Revisado en junio de 2012. Según se desprende de esta declaración, las críticas se refieren a la manera en que trabaja el MERCOSUR, pero no es un cuestionamiento existencial al bloque. Es decir, frente a las dificultades de la integración, se señala que es necesario mejorarla, de modo que contribuya adecuadamente a los intereses y a la inserción internacional de los países que participan del proceso. En el mismo tenor se refirió el Canciller brasileño Antonio de Aguiar Patriota quien, a propósito de la realización de la cumbre del MERCOSUR, celebrada en junio de 2012 en Mendoza, señaló que su país insistiría en la fórmula "Más Mercosur". Véase URL: <http://www.nuso.org/upload/articulos/ Apuntesdeintegracion6.pdf>. Revisado en junio de 2012. 
La integración es, por lo tanto, una relación entre unidades, en la cual éstas son mutuamente interdependientes y juntas producen propiedades del sistema de las que carecen por separado. Un aspecto fundamental de un sistema integrativo sería, por lo tanto, la producción de bienes públicos regionales relacionados con la capacidad de "trabajar juntos" y generar grados de predictibilidad en las conductas y comportamientos de los actores involucrados. Desde esta perspectiva, es posible apreciar que los ensayos de integración regional y subregional en América del Sur, al constituirse como foros de cooperación y diálogo, han favorecido un modelo estable y predecible de relaciones. Así, bajo la perspectiva de este trabajo, la integración tendería a bajar los costos de las transacciones, facilitando el intercambio de información y reduciendo la incertidumbre y las posibilidades de conflicto entre los países que participan del proceso.

Desde la teoría de la integración se ha planteado que dichos procesos presentan una dinámica "incrementalista", es decir, poseen una lógica expansiva que contribuye a extrapolar la integración, que en un principio suele aparecer como más visiblemente económica, hacia otras áreas de mayor contenido político. Este proceso puede ser calificado como "efecto bola de nieve". Es decir, la integración económica puede derramarse hacia otras áreas, como es el caso del ámbito estratégico y militar. Sobre el particular, Gustavo Magariños plantea que:

"En teoría, la integración una vez iniciada, aunque esté primeramente restringida a un sector, planteará progresivamente la necesidad de armonizar instrumentos y coordinar políticas en otras áreas. El ejercicio de una política exterior común induciría a adoptar un sistema de defensa coordinada y viceversa. La unión económica propulsará una mayor integración política y el establecimiento de una comunidad política tendría como consecuencia una integración económica más amplia y profunda" (Magariños, 2000:24).

De este modo, es posible sostener que la integración contribuye a la seguridad de los países que participan del proceso (Girault, 2009:86). Bajo esta perspectiva, en el Cono Sur la integración ha exhibido un efecto espiral en el ámbito estratégico, que se relaciona con el avance hacia una naciente comunidad de seguridad, en la cual los países resuelven sus disputas por medios alternativos a la guerra y la coacción, y que ha tendido a derramarse al nivel sudamericano.

Karl Deutsch plantea que, en un nivel general, un proceso de integración puede comprender el fomento de dos tipos de comunidades de seguridad: las amalgamadas, donde las unidades políticas antes independientes han formado una sola unidad con un gobierno común; y las pluralistas, que son más fáciles de establecer y en las que los gobiernos separados mantienen su independencia legal. Este segundo tipo de comunidades posee tres condiciones esenciales para su existencia:

1. Compatibilidad de los valores políticos fundamentales. 
2. Capacidad de los gobiernos y de los estratos políticamente importantes de los países participantes, para responder en forma recíproca a los mensajes, necesidades y acciones, en forma rápida, adecuada y sin recurrir a la fuerza.

3. Predictibilidad mutua de los aspectos relativos a la conducta política, económica y social de unos respecto de los otros (Deutsch, 1974: 231).

En esta línea, según Deutsch, una comunidad de seguridad se definiría por el logro, dentro de un territorio, de un sentido de comunidad y de instituciones y prácticas lo suficientemente fuertes y extendidas como para asegurar expectativas de cambio pacífico. Complementando estos postulados, Emmanuel Adler se refiere a las comunidades de seguridad en el contexto posterior al fin de la Guerra Fría. Según Adler (2001), a partir de ese momento el escenario internacional entraría en "la edad multilateral" (the multilateral age), caracterizada por los incentivos a la cooperación entre los países, sobre la base de valores y normas comunes, y por la pérdida de valor de los tradicionales recursos de poder de los Estados. Siguiendo a Deutsch, Adler define una comunidad de seguridad como una región compuesta por Estados soberanos cuyos pueblos mantienen mutuas expectativas de cambio pacífico (Adler, 2001:146).

Profundizando en el análisis de las comunidades de seguridad, Charles Kupchan señala que en éstas los Estados avanzan más allá de las mutuas perspectivas de relaciones pacíficas, para configurar consensualmente un conjunto de normas y reglas para guiar sus interacciones, institucionalizando códigos de conducta con miras al logro de intereses y objetivos conjuntos. En último término, la característica definitoria de una comunidad de seguridad sería la existencia de una identidad compartida entre las partes (Kupchan, 2010:183).

De este modo, es posible distinguir otros tres tipos de comunidades de seguridad. Una comunidad de seguridad naciente, donde los Estados miembros acuerdan superar sus disputas pacíficamente, identificando mecanismos rudimentarios para ello, y donde aún perviven las mutuas desconfianzas. Por otro lado, una comunidad de seguridad ascendente, en la cual los miembros acuerdan un más extensivo conjunto de normas y reglas de comportamiento, institucionalizando e incluso codificando esas pautas. Y por último, se puede distinguir una comunidad de seguridad madura, donde los Estados disfrutan de un orden constitucional en el cual un conflicto armado se hace impensable (Kupchan, 2010:184). Con base en lo anterior, es posible sostener que, en el contexto del MERCOSUR, se estaría en presencia de una comunidad de seguridad pluralista, en los términos sugeridos por Deutsch, y naciente, en la conceptualización de Kupchan. Como se verá más adelante, estos avances en el Cono Sur serían proyectados a nivel regional, donde destaca el desarrollo que exhibe la UNASUR y el Consejo de Defensa Suramericano. De este modo, si bien aún perviven disputas no resueltas, desconfianzas y competencias bilaterales entre algunos países de América del Sur -como es el caso entre Colombia y Venezuela, Venezuela y Guyana, Bolivia y Chile, Ecuador y Perú, Chile y Perú, entre otros-, lo cierto es que 
dichas problemáticas se canalizan a través de negociaciones y mecanismos políticos, antes que mediante la coerción y la fuerza física.

Complementando el análisis sobre los efectos de las formaciones regionales en la seguridad internacional, Barry Buzan y Ole Wæver (2003) plantean la teoría de los Complejos de Seguridad Regional, la cual se centra en la región como unidad independiente de análisis. En tal sentido, sostienen que en un escenario interdependiente, la seguridad de los países depende directamente de su entorno inmediato. Es decir, según estos autores, la mayoría de las amenazas viajan más fácilmente a través de cortas distancias que a través de las largas. Por lo tanto, en el análisis de la seguridad de los países, éstos no pueden ser sustraídos de su entorno regional, pues la base de la seguridad internacional se fundamenta en las relaciones entre los distintos actores, principalmente los vecinos y próximos, ya que éstos por lo general se consideran la mayor fuente de inseguridad, aunque también son parte fundamental de las soluciones.

Respecto del hemisferio, Buzan y Wæver sostienen que Norteamérica y Sudamérica exhiben diferentes dinámicas de seguridad y altos niveles de asimetrías. Por una parte, América del Norte estaría determinada por la existencia de un gran superpoder. Por otra, el complejo sudamericano estaría compuesto por el área andina y el Cono Sur, representando cada uno de estos un subcomplejo (Buzan \& Wæver, 2003:263). La teoría de Buzan y Wæver presupone la existencia de subsistemas regionales para analizar las cuestiones de seguridad, en tanto un complejo de seguridad es definido como un conjunto de Estados cuyas preocupaciones y desafíos están tan vinculados y entrelazados, que sus respectivos problemas de seguridad nacional no pueden ser analizados de manera autónoma.

\section{EI MERCOSUR EN LA REALIDAD REGIONAL}

En el ámbito sudamericano, desde comienzos de los años noventa se planteó una tendencia a la convergencia en materia de seguridad e integración, liderada por Brasil y Argentina. Luego de la denominada década perdida, esta convergencia se originó en la idea de que una integración económica no podía ser sostenida en el largo plazo sin alcanzar acuerdos en el plano estratégico y de seguridad. Para ello, debían desactivarse las percepciones de amenaza convencionales a la seguridad de los Estados, que persistían desde la época de las dictaduras militares. En tales circunstancias, es evidente que el MERCOSUR fue creado por razones estratégicas, que superan una perspectiva meramente comercial.

Desde un prisma político, hacia la segunda mitad de la década de los ochenta, el MERCOSUR tuvo como antecedentes una serie de encuentros, declaraciones y acuerdos entre los entonces presidentes Raúl Alfonsín (Argentina) y José Sarney (Brasil), que encabezaban los primeros gobiernos del Cono Sur que vivían procesos de transición a la democracia. De este modo, se desarrollaba en la subregión una tendencia integradora en lo económico y comercial, que 
tuvo como correlato el reforzamiento de los mecanismos e instancias de diálogo y concertación política.

De tal manera, las políticas de enfrentamiento en el Cono Sur, la competencia por el liderazgo militar y las diferencias y conflictos limítrofes fueron moderados o desplazadas por una tendencia creciente hacia la cooperación, como la mejor opción para construir una ambiente de paz y seguridad en la subregión, y como una condición esencial para impulsar la inserción internacional de los países. Ello posibilitó un cambio fundamental en las relaciones entre Argentina y Brasil, lo que permitió un decidido avance en el proceso de integración. El 6 de julio de 1990 los presidentes Carlos Menem y Fernando Collor de Mello firmaron el Acta de Buenos Aires, en la que se aceleraron los plazos para poner en marcha el mercado común. En agosto del mismo año, Paraguay y Uruguay se unieron al proceso, por lo que el 26 de marzo de 1991, los Presidentes de Argentina, Brasil, Uruguay y Paraguay firmaron en Asunción el tratado del mismo nombre, dejando en consecuencia constituido el MERCOSUR.

Como es posible observar, tras el fin de la Guerra Fría, Brasil y Argentina asumieron políticas exteriores de inserción internacional y establecieron el MERCOSUR como una estrategia para adaptarse a las nuevas condiciones del escenario mundial, estando el acercamiento argentinobrasileño contextualizado por la aceleración del proceso de globalización, la convergencia entre los países del Cono Sur en lo tocante a las políticas económicas y las transiciones hacia la democracia, en el marco de lo que desde la ciencia política se dio en calificar como la "tercera ola democrática". El acercamiento y distensión entre los actores principales de la región, así como los cambios políticos y la convergencia económica posibilitaron el desarrollo de la integración entre los países que posteriormente conformarían el MERCOSUR. La integración no sólo se concebía desde una perspectiva meramente económica y comercial, sino que se consideró el factor político como una condición decisiva. De hecho, según Fred Bergsten (1996), de manera similar a la Unión Europea, que en sus orígenes buscaba poner término a la histórica rivalidad entre Francia y Alemania y dotar de paz a Europa luego de las terribles consecuencias derivadas de la Segunda Guerra Mundial, entre otros ámbitos, el MERCOSUR buscaba poner fin a la carrera armamentista y a la competencia estratégica entre Argentina y Brasil, incluida su dimensión nuclear.

Teniendo como base estos elementos estratégicos y de seguridad, desde sus inicios el MERCOSUR tuvo un carácter más visiblemente económico, que desde mediados de la década de los noventa comenzó a evidenciar problemas en torno a las dificultades de remover las barreras arancelarias, las políticas económicas internas que afectaban la competencia, así como el trabajo de hacer efectiva la aplicación de las normas del bloque. En efecto, según sostiene Natividad Lorenzo (2006), desde su creación en 1991 y hasta 1998, el MERCOSUR evidenció importantes logros en la esfera comercial. En esta fase, se logró liberalizar la totalidad de los productos comprometidos para esta etapa y aplicar un arancel externo común al 88\% del universo arancelario de la subregión. Estos avances atrajeron capitales y aumentaron la inversión extranjera 
directa, creando un clima propicio para la integración. Sin embargo, la crisis económica y financiera que sufrió la región hacia fines de la década de los noventa, marcaron el fin de esta etapa favorable, iniciándose un nuevo periodo donde priman los intereses nacionales en las relaciones al interior del bloque, estancándose los flujos del comercio intrarregional, a lo que se une la pérdida de confianza de los inversores extranjeros y la fuga de capitales (Lorenzo, 2006: 2).

De tal modo, en el terreno comercial, diversas problemáticas marcan actualmente la realidad del MERCOSUR. Entre las diversas críticas que se han planteado al bloque, está el que dicha instancia carece de una dimensión comunitaria y supranacional, caracterizándose por una estructura orgánica escueta y de carácter meramente intergubernamental. En la misma línea, Lorenzo señala que el MERCOSUR se caracteriza por ser un proyecto de escasa calidad institucional, poca disciplina de los miembros, falta de incorporación de normas, reuniones de bajo nivel con escasa calidad técnica y falta de orden interno. Esto ha impulsado a los países pequeños a buscar nuevas opciones de asociación comercial; a ello se suma la falta de una visión común y de un liderazgo definido en el proceso de integración, ante la omisión del rol natural que debiera ejercer Brasil, más empeñado en su posicionamiento como potencia emergente en otras instancias internacionales (Lorenzo, 2006).

No obstante, estas vicisitudes económicas y comerciales han encontrado como contrapartida una creciente interrelación en otras áreas, como la tecnología, ciencia, educación, migraciones y aspectos vinculados con la cooperación estratégica y militar (Molina, 2000:28; Pey \& Riquelme, 2007). Es decir, las dificultades y estancamientos del MERCOSUR en el área comercial no han mermado una de las principales fortalezas del bloque, tal como su notable sentido político, que ha implicado la promoción de un ambiente de paz y estabilidad en el Cono Sur, y ha contribuido a fortalecer la democracia entre los miembros.

Según Gabriel Gaspar (2003:31), si bien han existido importantes diferencias entre los países del MERCOSUR y sus asociados, apreciándose en el terreno económico ciertas vicisitudes de las economías nacionales, no ha ocurrido lo mismo en el ámbito político. Según este autor, los logros de la concertación son evidentes. De esta manera, el "MERCOSUR político" mostraría más logros que el "MERCOSUR económico", cuestión que se expresaría en los temas de seguridad. Es decir, más allá de las dificultades que se aprecian en su desempeño económico, lo cierto es que el MERCOSUR ha sido particularmente exitoso en su contribución a la consolidación democrática y al mantenimiento de la paz en el Cono Sur. En consideración de estos aportes, según Félix Peña (2008), la idea de colapso no es sostenida por ninguno de los gobiernos del bloque, los que más bien sostienen la necesidad de llevar a cabo iniciativas concretas que permitan, a través de metodologías flexibles, aumentar su eficiencia y renovar su legitimidad.

En consecuencia, desde la perspectiva de este trabajo, el MERCOSUR se ha constituido como una instancia relevante para fomentar la paz entre sus miembros plenos y asociados, lo que ha 
tenido como efecto el creciente desarrollo de una comunidad pluralista de seguridad en el Cono Sur, que ha tendido a derramarse al nivel sudamericano.

2.1. La carencia de un liderazgo definido en la región. En los términos planteados por Félix Peña (2008:26), un liderazgo regional conlleva distintos conceptos entrelazados. Primero, el concepto de relevancia, que se relaciona con el grado de gravitación (poder, recursos, mercado, influencia y prestigio) que un país puede tener para definir la manera como son encaradas cuestiones importantes de la agenda regional. Luego, es preciso definir el concepto de protagonismo, que significa que un país, especialmente si es relevante, procura tener una presencia activa como actor en las cuestiones importantes de la agenda de la región. Por último, se debe subrayar que el concepto de liderazgo implica que un país opte por ser un protagonista activo, cualquiera que sea su relevancia, y contribuir a las cuestiones con una visión estratégica y con iniciativas aceptables para los demás países.

En un nivel general, el papel de los liderazgos resulta fundamental para entender los procesos de integración y la estabilidad internacional. Desde la teoría de la integración, los liderazgos son definidos como "centros de poder", que actúan como catalizadores del cambio de poder internacional, y que son vitales para todo proceso integrativo. El liderazgo franco-alemán fue esencial para avanzar en el proceso de integración europeo luego de la Segunda Guerra Mundial. En el ámbito sudamericano, por su parte, los ensayos de integración actuales han contado con diversos respaldos nacionales, como es el caso de Brasil y Argentina en la constitución del MERCOSUR, Venezuela en el ALBA y nuevamente Brasil en la UNASUR, por mencionar algunos ejemplos.

Desde la teoría de la integración el papel de los líderes en los procesos de integración ha sido profusamente analizado. Como se indicó, bajo esta perspectiva, se postula que, para el avance de la integración, resulta imprescindible un área focal o centro de poder que impulse el proceso. Sin embargo, la débil consolidación de los ensayos de integración más arriba expuestos, puede explicarse por la carencia de un liderazgo firme, constante y definido en la región, razón por la cual la experiencia sudamericana todavía parece lejos del ejemplo europeo.

América del Sur actualmente se aprecia como un espacio geopolítico con un centro mayor, que sería Brasil, cuyo papel en la región es contestado por las aspiraciones de Venezuela, y luego por Argentina. En este punto aparecen nuevos actores pujantes, como es el caso de Chile, Colombia y Perú. No obstante, los papeles de liderazgo perseguidos por Brasil y Venezuela responden a visiones distintas sobre el nuevo escenario multipolar que se desarrolla en el mundo. Además, cabe anotar que el liderazgo de Venezuela se verá sin duda afectado tras la reciente muerte del Presidente Hugo Chávez, cuyo carisma parece difícil de replicar por otro líder de ese país. Asimismo, en el marco del eje ALBA tampoco se avizora un nuevo liderazgo nacional de tal envergadura, ya sea en el caso de Rafael Correa en Ecuador, Evo Morales en Bolivia, o Raúl Castro en Cuba. 
En el marco regional, según sostiene Andrés Serbin (2009:147), la perspectiva de Venezuela manifiesta un carácter marcadamente geoestratégico y militar, cargado de elementos ideológicos. El autor plantea que, mediante una diplomacia proactiva que utiliza los recursos energéticos, en el marco de iniciativas como Petrocaribe, Hugo Chávez pretendió fortalecer su liderazgo regional, al mismo tiempo que asumir un papel global más relevante a través de alianzas con Irán, Rusia y China y la utilización de la Organización de Países Exportadores de Petróleo (OPEP), de la mano de una retórica fuertemente antiimperialista.

En lo tocante al ámbito estratégico militar, cabe señalar que este es un punto todavía embrionario en el marco del ALBA. María Cristina Silva (2011) plantea que no existen dentro de esta iniciativa acuerdos acabados grupales de cooperación militar o relativos a la defensa regional. Solo recientemente en la VII Cumbre del ALBA, celebrada en octubre de 2009 en Cochabamba, se gestó una primera iniciativa para institucionalizar la seguridad en el ALBA, al decidirse la conformación de un Comité Permanente de Soberanía y Defensa, que formaría parte del Consejo Político del ALBA. El Comité tiene como objetivos "la definición de una Estrategia de Defensa Integral Popular Conjunta y la constitución de una Escuela de Dignidad y Soberanía de las Fuerzas Armadas". Los acuerdos entre los países del ALBA mantienen un carácter predominantemente bilateral, como son los sucesivos acuerdos militares entre Venezuela y Bolivia, o los acuerdos militares bilaterales de Venezuela con países observadores del ALBA, como son Irán y Rusia. Hasta el momento los llamados de la Venezuela chavista por conformar un órgano de seguridad común antiimperialista no se han concretado, por lo que los avances en esta línea parecen todavía modestos (Silva, 2011)².

Por otro lado, en lo relativo al liderazgo de Brasil, cabe señalar que posee un carácter moderado, con una diplomacia pragmática, basada en el desarrollo de la economía y el comercio y en una opción de convivencia con Estados Unidos. A este respecto, puede señalarse que la política exterior del gigante sudamericano se despliega en tres geografías. La primera es la que vincula el Sur con el Norte, donde destaca la relación con Estados Unidos. La segunda tiene que ver con la dinámica Sur-Sur, donde Brasil puede lograr una mayor proyección de poder e influencia, y que se concreta en iniciativas tales como IBSA (India, Brasil y Sudáfrica) y BRICS. La última geografía es América del Sur, donde resalta el liderazgo brasileño en la constitución de la Comunidad Sudamericana de Naciones (hoy UNASUR) y el Consejo de Defensa Suramericano (Merke, 2012).

En el mismo tenor, cabe destacar que Brasil aspira a convertirse en un actor de nivel global, basado en la consolidación de su liderazgo regional con un papel de relevancia en el seno del

2. En este punto, cabe señalar que la alianza entre Venezuela e Irán ha despertado reacciones en diversos sectores de la región, al apreciarse que extrapola el conflicto de Medio Oriente a América del Sur. Venezuela identifica a Israel como enemigo, lo que ha desatado la respuesta de este país mediante un reforzamiento de la cooperación militar con Colombia. De tal modo, se han planteado críticas al accionar venezolano, en tanto puede implicar una amenaza al objetivo de UNASUR acerca de consolidar una Zona de Paz (Silva, 2011, p. 254). 
G-20, el BRICS e IBSA, entre otros, apuntando en último término a alcanzar un asiento permanente en el Consejo de Seguridad de las Naciones Unidas, en el marco de la reforma de la Organización. Sin embargo, este último objetivo requiere, como condición sine qua non, del apoyo unánime de los países de la región, lo que actualmente parece poco probable.

En consecuencia, si bien es posible percibir las aspiraciones de Brasil y Venezuela para configurarse como líderes de la región -Argentina, con sus vicisitudes internas y externas, se ha apreciado últimamente con poco éxito en esta carrera-, en un contexto general marcado por la carencia de un líder constante y sostenido, lo cierto es que, por su dimensión relativa, el primero parece tener una mayor potencialidad para influir e incidir en las cuestiones regionales, aunque igualmente por necesidad requiere para ello del acuerdo de otros actores relevantes, como es el caso de Argentina, Colombia, Chile, Perú y, desde luego, Venezuela. No obstante, Brasil no ha manifestado impulsos constantes por configurarse como líder regional, preocupado, tal vez, de fortalecer su posicionamiento internacional a través de foros como el G-20, BRICS o IBSA.

\section{El MERCOSUR DESDE UNA PERSPECTIVA ESTRATÉGICA}

El contexto hemisférico se caracteriza por la obsolescencia y debilidad en los mecanismos institucionales del ámbito de la seguridad y la defensa, lo que se ha expresado en fuertes críticas a la institucionalidad de la Organización de Estados Americanos (OEA). Aparte de los cuestionados Tratado Interamericano de Asistencia Recíproca (TIAR) y la Junta Interamericana de Defensa (JID), prácticamente no existen instrumentos de prevención de conflictos adecuados, por lo que más bien se han producido avances en las respectivas regiones y subregiones, mediante el establecimiento de mecanismos de coordinación política, de cooperación o de acuerdos y declaraciones que pretenden dotar de una mayor coherencia y estabilidad las relaciones entre los países, como es el caso del MERCOSUR y UNASUR.

Pese a la persistencia de ciertos roces bilaterales, como las últimas divergencias suscitadas entre Brasil y Argentina por las medidas proteccionistas adoptadas por este último, o las tensiones acontecidas entre Argentina y Uruguay por el denominado "conflicto de las papeleras" (Ghitis, 2006; Flemes \& Radseck, 2009), lo cierto es que el MERCOSUR se ha constituido en un marco de relevancia para un proceso de convergencia en los planos de la seguridad y la defensa en el Cono Sur, con efectos de derrame a nivel sudamericano. Como núcleo duro de la integración regional, el MERCOSUR ha tenido como consecuencia en el Cono Sur el que la asociación económica haya acarreado el progresivo desmantelamiento de las antiguas precauciones en el ámbito militar. De tal modo, las hipótesis de conflicto han dado paso a las iniciativas de cooperación, lo que ha cambiado las relaciones internacionales y las percepciones de amenaza en las respectivas fuerzas armadas. 
Estos procesos han estado contextualizados en una región que, desde la literatura politológica, ha sido caracterizada como una "zona de paz", en términos de los tradicionales conflictos interestatales, pero que desde la perspectiva de las denominadas "nuevas amenazas", ha estado marcada, sobre todo a partir de principios de este siglo, por el rápido desarrollo del crimen organizado, el tráfico de drogas, el tráfico de armas y la migración ilegal (Kacowicz, 2008). Estas amenazas han planteado a los países la necesidad de un enfrentamiento coordinado, lo que ha incrementado las posibilidades para la cooperación.

El acercamiento de los países que participan del MERCOSUR, ya sea como miembros plenos o asociados, se ha expresado, en el terreno estratégico, en una fluida cooperación bilateral de las políticas de defensa, que ha sido particularmente evidente en las relaciones entre Brasil y Argentina, y entre éste último país y Chile, lo que hace pensar en una suerte de reedición del $A B C$ de principios del siglo XX. En el terreno de la cooperación militar, el acercamiento se ha expresado en conferencias, reuniones, ejercicios conjuntos, cooperación técnica y programas de intercambio entre las academias de las respectivas fuerzas armadas. Según Daniel Flemes (2004a), el centro de gravedad de la cooperación ha sido el relacionamiento argentino-brasileño. En esta línea, Marcos Robledo y Francisco Rojas han sostenido lo siguiente:

"los países que participan en el proceso de desarrollo del régimen subregional de integración han ingresado en una etapa de cambio estratégico que, a pesar de las divergencias que persisten, origina una clara tendencia hacia el desarrollo de regímenes cooperativos de seguridad y defensa, siendo esperable que al no visualizarse modelos alternativos, la cooperatividad se consolide y profundice" (Robledo \& Rojas, 2002, p. 18).

La institucionalización de la cooperación del ámbito político y estratégico, en el marco del bloque, vivió importantes avances el año 1998, a partir de la Cumbre de Presidentes del MERCOSUR, realizada los días 24 y 25 de julio, donde participaron los mandatarios de los Estados miembros plenos y de los Estados asociados. En el evento se firmó el Protocolo de Ushuaia, que instituyó la denominada cláusula democrática. Teniendo en cuenta los conflictivos sucesos que acontecían en Paraguay, ésta ratificó lo que con anterioridad se había expresado en la Declaración de las Leñas del 26 y 27 de julio de 1992, en torno a que la plena vigencia de las instituciones democráticas era una condición indispensable para la existencia y desarrollo del MERCOSUR. Una vez más, en el año 2012, Paraguay estuvo en el centro de los debates al interior del bloque, luego de su suspensión, debido a la destitución del Presidente Fernando Lugo. La salida de Paraguay, además, posibilitó la súbita entrada de Venezuela al MERCOSUR como miembro pleno, que estaba estancada en el Congreso paraguayo, lo que de paso ha puesto en entredicho la normativa del bloque, así como deja entrever eventuales conflictos por las disputas por el liderazgo y por las distintas percepciones de los países acerca de la propuesta bolivariana del recientemente desaparecido Chávez. 
Pero de manera más fundamental, en el terreno estratégico, debe destacarse la "Declaración Política del MERCOSUR, Bolivia y Chile como Zona de Paz", durante la XIV Reunión del Consejo del MERCOSUR, realizada en Ushuaia el 24 de julio de 1998. En esta Declaración se sostiene que la paz constituye una base fundamental para el desarrollo y representa una condición primordial para la existencia y continuidad del MERCOSUR, presentando la seguridad como un elemento esencial para el desarrollo de los pueblos. En concreto, la "Declaración del MERCOSUR, Bolivia y Chile como Zona de Paz", indica, entre otros, los siguientes puntos:

1. Declarar al MERCOSUR, Bolivia y Chile como zona de paz y libre de armas de destrucción masiva.

2. Manifestar que la paz constituye un elemento esencial para la continuidad y desarrollo del proceso de integración del MERCOSUR.

3. Fortalecer los mecanismos de consulta y cooperación sobre temas de seguridad y defensa existentes entre sus miembros y promover su progresiva articulación, así como avanzar en la cooperación en el ámbito de las medidas de fomento de la confianza y la seguridad y promover su implementación.

4. Apoyar en los foros internacionales pertinentes la plena vigencia y el perfeccionamiento de los instrumentos y mecanismos de no proliferación de armas nucleares y otras de destrucción masiva.

5. Realizar esfuerzos conjuntos en los foros internacionales pertinentes para avanzar, en el marco de un proceso gradual y sistemático, en la consolidación de acuerdos internacionales orientados a lograr el objetivo del desarme nuclear y la no proliferación en todos sus aspectos.

6. Avanzar en la consagración del MERCOSUR, Bolivia y Chile como zona libre de minas terrestres antipersonales y procurar extender tal carácter a todo el hemisferio occidental.

7. Reafirmar su compromiso de ampliar y sistematizar la información que proveen al Registro de Armas Convencionales de las Naciones Unidas y establecer una metodología uniforme para informar sobre el gasto militar, con miras a aumentar la transparencia y el fomento de la confianza en la materia.

Así pues, en base a las iniciativas e instancias políticas llevadas a cabo al interior del bloque, puede sostenerse que, con algunos obstáculos -como la escasa institucionalización de la integración- se ha avanzado de manera paulatina hacia la conformación de una comunidad pluralista de seguridad, en la que los Estados -que mantienen su independencia legal- solucionan sus conflictos por otros instrumentos políticos antes que a través de la guerra y la coerción. Como se 
explicará con mayor detenimiento más adelante, este proceso ha tendido a derramarse a nivel sudamericano, donde se aprecian importantes avances con la creciente consolidación que expresa UNASUR y, en su marco, el Consejo de Defensa Suramericano.

No obstante, en el Cono Sur la cooperación no ha decantado en la formalización institucional de un sistema de seguridad, aunque el acercamiento y la distensión son evidentes. Los países que participan en el MERCOSUR se han asociado para impulsar valores y políticas comunes en torno al fortalecimiento de la democracia, economías de mercado crecientemente abiertas - pese a las últimas tendencias que evidencia Argentina- y variados grados de concertación política intergubernamental, como una manera de optimizar la plena e integral inserción internacional y la proyección de sus valores e intereses.

De tal modo, según Francisco Rojas (2002), el desarrollo de esta concertación política ha producido un cambio estratégico que ha permitido el desarrollo de un proceso de construcción de un régimen cooperativo de seguridad subregional, articulado sobre un conjunto de valores políticos y de intereses comunes en el ámbito de la seguridad, además de un fuerte desarrollo de regímenes bilaterales de cooperación y de asociación. Según Rojas, un régimen de seguridad cooperativa corresponde a una situación de seguridad estatal, basada en: a) en la ausencia de conflictividad sustantiva entre dos o más Estados; b) en el desarrollo de estrategias coordinadas de búsqueda de una "seguridad común"; y c) la necesidad de respuestas internacionalmente coordinadas (Rojas, 2002). De esta manera, la seguridad cooperativa se diferencia de la seguridad colectiva, en tanto que esta contempla un sistema supranacional centralizado de seguridad, que se orienta hacia la defensa de agresiones externas y al mantenimiento de la paz entre los miembros. Como es posible apreciar, un mecanismo de estas características exigiría un nivel más profundo de integración que el que actualmente existe en la subregión.

La baja densidad de la institucionalidad en el terreno defensivo, susceptible, al mismo tiempo, de ser interpretada como alta flexibilidad, se explica, en parte, por la voluntad política de los Estados de mantener cotos de soberanía reservados a los ámbitos nacionales, así como por la heterogeneidad que se aprecia entre los miembros plenos y asociados del bloque en torno a sus concepciones acerca de la seguridad y la defensa, lo que consecuentemente afecta las percepciones de los países sobre el empleo de las fuerzas armadas. Tales diferencias, que también se aprecian en el resto de los países de la región, igualmente podrían afectar los avances y actividades del Consejo de Defensa Suramericano.

Entonces, si bien aún existen en el MERCOSUR ciertas vicisitudes y diferencias entre los Estados, de todos modos, puede sostenerse que aquel ha sido el escenario de una dinámica integradora que ha implicado la disminución de las percepciones de amenazas militares, y una tendencia a la negociación y el diálogo en la resolución de las diferencias. Por lo demás, muchas de las diferencias y roces entre los países obedecen a otros factores, como la vecindad, no siendo atribuibles al MERCOSUR. Más bien, este proceso de integración ha impulsado 
el acercamiento, al constituirse como un foro propicio para el diálogo y como un marco contextual que ha puesto a los países a "trabajar juntos".

3.1. Cooperación militar en el Cono Sur. Como se ha planteado en este artículo, el MERCOSUR ha contribuido a la estabilidad en la región, pues ha generado un entramado de objetivos y relaciones que han profundizado los vínculos políticos y económicos entre los miembros. Ello se ha manifestado en el impulso de intereses cruzados y al fomento de un escenario interdependiente y común para los países. En el mismo orden de ideas, Marcela Donadio (2000) sostiene que las políticas de enfrentamientos cruzados, las competencias por el liderazgo militar y los problemas limítrofes, han sido desplazados desde la década de los noventa por una tendencia creciente en los países del Cono Sur a considerar que la cooperación constituye la mejor opción para construir un ambiente de paz y seguridad.

Así pues, las antiguas prevenciones en el plano defensivo militar y las respectivas hipótesis de conflicto han cedido paulatinamente el lugar a la cooperación en el terreno de la seguridad y la defensa, aunque no se haya llegado aún al establecimiento de un sistema institucionalizado de seguridad en el bloque. En esta misma línea, Robledo y Rojas (2002) plantean que la principal característica de este régimen de facto ha sido su opción por la concertación y coordinación política intergubernamental como modalidad institucional. Según estos autores, el bloque ha evitado el desarrollo de instituciones supraestatales y la adopción mecánica de la jerarquía integracionista europea, pues ningún actor del proyecto integrador habría planteado la unión política y la supranacionalidad como objetivo final del proceso de integración.

En el terreno de la cooperación militar, y como una manera de otorgar operacionalidad a la Declaración Política del MERCOSUR como Zona de Paz de 1998, desde abril de 2001 se realiza la Reunión de Comandantes en Jefe de los Ejércitos de los países integrantes del MERCOSUR, en cuyo seno se han discutido temas como la definición de una agenda de defensa en esta instancia, el mejoramiento en los niveles de interoperabilidad entre las fuerzas armadas y la ayuda ante casos de desastres naturales ${ }^{3}$, entre otros. Además de las reuniones de Comandantes en Jefe del MERCOSUR, en diciembre de 2007, en el marco del Foro de Consulta y Concertación Política, se decidió crear el Grupo de Trabajo sobre Prevención de Proliferación de Armas de Destrucción Masiva (GTADM).

En el Cono Sur, la manera más expedita para avanzar en la profundización de la cooperación en seguridad y defensa ha sido conducida por el camino predominantemente bilateral y trilateral. En las relaciones bilaterales chileno-argentinas, destaca la existencia de diversos

3. A este último respecto, cabe destacar el primer Ejército de Operaciones de Ayuda en caso de Desastres del Comité de Comandantes en Jefe de los Ejércitos de los Países del MERCOSUR y Asociados (CCEPMA), donde participaron en ejercicios en Ecuador el año 2007 efectivos de Bolivia, Brasil, Colombia, Chile, Ecuador, Paraguay, Perú, Uruguay y Venezuela (Yopo, 2009, p. 9). 
arreglos durante la década de los noventa y significativos cambios en las operaciones militares combinadas entre las fuerzas armadas. También cabe destacar las negociaciones por los límites del monte Fitz Roy y el cerro Daudet, que solucionaron gran parte de las disputas territoriales entre ambos países. En noviembre de 1995 Argentina y Chile firmaron el Memorándum de Entendimiento para el Fortalecimiento de la Cooperación en Materia de Seguridad de Interés Mutuo, a través del cual se creó el Comité Permanente de Seguridad (COMPERSEG), integrado por representantes de los Ministerios de Relaciones Exteriores y de Defensa, con la finalidad de establecer una agenda de trabajo que permitiera la profundización de la cooperación entre ambos países en el ámbito estratégico. Desde su creación, el COMPERSEG ha asegurado un continuo diálogo político en torno a las materias de seguridad entre Argentina y Chile, fortaleciendo la cooperación y el intercambio entre los actores civiles y militares.

Las reuniones del citado Comité han arrojado como resultado, entre otros avances, el diseño y aplicación de índices estandarizados de medición de gastos militares, con el apoyo de la CEPAL, así como el desarrollo de ejercicios y actividades conjuntas y combinadas entre las respectivas fuerzas armadas. Por ejemplo, se han efectuado ejercicios conjuntos en una Patrulla Antártica Naval chileno-argentina; en 1999 se reparó en los astilleros de ASMAR Chile el destructor argentino Hércules; también cabe subrayar la existencia de un acuerdo para la construcción conjunta de buques para las armadas (véase Garay, 2003:95; Rojas, 2002; Griffiths, 2006). Especialmente destacable resulta la creación de la fuerza binacional de paz Cruz del Sur entre Chile y Argentina en diciembre del año 2006, una iniciativa sin precedentes en la región, que demuestra la madurez y consolidación política de la relación de ambos países.

En la esfera política, el nivel de confianza entre ambos países quedó demostrado durante el intercambio de visitas que realizaron a mediados de 2012 los Ministros de Defensa de ambos países. El Ministro de Defensa chileno, Andrés Allamand, estuvo en Argentina para participar, junto con un contingente de cadetes, en los actos conmemorativos de la muerte del General San Martín. También visitó las instalaciones donde se desarrolla un proyecto de lanzamiento de vectores, base de la capacidad militar. Días después, su par argentino, Arturo Puricelli, estuvo en Santiago. Durante la visita, entre otros asuntos, se analizó el futuro de la fuerza de paz Cruz del Sur.

En el ámbito de la relación chileno-peruana, y más allá del diferendo limítrofe llevado a la Corte Internacional de Justicia, cabe destacar que el 16 de noviembre de 2012 se celebró en Torre Tagle la $\vee$ Reunión del Comité de Seguridad y Defensa Perú-Chile (COSEDE), mecanismo institucionalizado para el diálogo y la cooperación en materia de seguridad, defensa y fortalecimiento de la confianza mutua. La agenda de la reunión, que se realizó luego de seis años, permitió reiniciar las conversaciones entre ambos países en torno a una metodología para la medición de los gastos en defensa, renovar el compromiso para incrementar la cooperación y coordinación en la lucha contra los delitos transnacionales en la zona fronteriza y concertar posiciones comunes en foros multilaterales del ámbito de la defensa, entre otros temas relevantes. 
Una relación especialmente importante en el contexto subregional y regional es la argentinobrasileña. Sobre el particular, se debe subrayar la existencia del Mecanismo de Consulta y Coordinación entre Argentina y Brasil en materia de Defensa y Seguridad Internacional, establecido a partir de 1997, en el cual participan los Ministros de Relaciones Exteriores y de Defensa de ambos países. En consideración de este avance, en abril de 1997 los respectivos Presidentes concordaron en la Declaración de Río de Janeiro que:

“...esta alianza existe porque tenemos una firme comunión de valores. Nuestras sociedades son democráticas, plurales, defienden las libertades, los derechos humanos y la libre iniciativa como medio de promover la prosperidad, así como la justicia social como medio de asegurar la concordia como fundamento de nuestro modo de vida" (véase Diamint, 1999, p. 54).

El dinamismo de las relaciones fue patente durante la visita que el Ministro de Defensa de Brasil, Celso Amorim, realizó a Buenos Aires en septiembre de 2011, donde se reunió con su par argentino, brindó una conferencia en la Escuela de Defensa Nacional y se reunió con la Presidenta Cristina Fernández. Durante el encuentro bilateral, las delegaciones abordaron las áreas de cooperación en torno a la profundización del diálogo político-estratégico; los proyectos comunes en ciencia, tecnología y producción en defensa; cooperación militar y proyectos comunes sobre la Antártica y el Atlántico Sur ${ }^{4}$.

En abril de 2012, en una nueva reunión entre los Ministros de Defensa de ambos países, esta vez en Brasilia, se dialogó sobre la continuación del desarrollo de una estrategia común para el desarrollo científico-técnico en el campo de la defensa, así como respecto de la UNASUR y el Consejo de Defensa Suramericano. Durante el evento, Amorim señaló que "la relación con la Argentina es la más estratégica de todas las relaciones".${ }^{5}$ En esa ocasión, ambas autoridades coincidieron en la necesidad de profundizar los temas de la agenda bilateral, tales como los relativos a la capacitación y entrenamiento de las escuelas militares, la relación entre las industrias para la defensa de Argentina y Brasil y la necesidad de avanzar en los ámbitos de la defensa cibernética y la asistencia entre los países ante situaciones de desastres naturales. Por último, como ejemplo de las fluidas relaciones entre ambos países, cabe destacar igualmente el proyecto Gaucho, para fabricar un vehículo blindado y el desarrollo de un satélite conjunto.

También, desde el año 2000, Brasil ha estado trabajando bilateralmente con otros países de la región, en el marco de los Grupos de Trabajo Bilateral de Defensa. Tales instancias de diálogo

4. Véase URL: <http://www.infodefensa.com/?noticia=argentina-y-brasil-profundizan-sus-lazos-en-materia-de-defensa>. Revisado en junio de 2012.

5. Véase URL: <http://www.infodefensa.com/?noticia=argentina-y-brasil-profundizan-agenda-bilateral-en-materia-dedefensa>. Revisado en junio de 2012. 
pretenden intensificar los lazos existentes de cooperación, intercambio e integración entre las respectivas fuerzas armadas. Resulta ilustrativa, además, la inspección conjunta de las fuerzas de paz por parte de los Ministros de Defensa de Brasil, Chile y Uruguay en Haití el mes de julio de 2004. En esa ocasión, la Ministra de Defensa de Chile sostuvo que:

"Esto nos ayuda a contribuir a la paz en nuestra región. Trabajar juntos en terreno nos ayuda a ser más amigos y a enfrentar temas difíciles. Vamos a estar allá en un esfuerzo muy importante para nosotros, es un esfuerzo latinoamericano, que hacemos por primera vez en la historia. Por eso es muy importante para nosotros ir junto con los ministros de Brasil y Uruguay a Haití". ${ }^{6}$

Como se ha señalado, la colaboración militar se ha manifestado en conferencias, ejercicios conjuntos, intercambio de personal y cooperación técnica, entre otros. En lo relativo a las actividades entre los ejércitos, cabe indicar los ejercicios Transamérica (donde participan Argentina, Brasil y Uruguay), Cruz del Sur (Argentina, Brasil, Paraguay y Uruguay), Cabañas (Argentina y Brasil) y Lazo Fuerte (Argentina y Brasil), entre otros. Respecto de las fuerzas aéreas, cabe mencionar los ejercicios Tanba (Argentina y Brasil), Prata (Argentina y Brasil) y Cruzex (Argentina, Brasil, Chile, Francia y Uruguay). Las fuerzas navales han realizado, por ejemplo, los ejercicios Fraterno (Argentina y Brasil), Post Fraterno (Argentina, Brasil y Uruguay), Coamas (Argentina, Brasil, Paraguay y Uruguay), Diplomex (Argentina, Brasil y Uruguay), Araex (Argentina y Brasil) y Acrux (Argentina, Bolivia, Brasil, Paraguay y Uruguay).

Junto con todo lo anterior, deben nombrarse las actividades de desminado, cuyo desarrollo ha contribuido de manera relevante a la confianza de los países del Cono Sur y a la interacción y diálogo de autoridades civiles y militares. Es el caso del desminado humanitario llevado a cabo en el Parque Nacional Llullaillaco en febrero de 2006, al cual asistieron autoridades chilenas, bolivianas y argentinas ${ }^{7}$.

Entre otros factores, la formación de una comunidad de seguridad requiere del aumento de la interacción entre los actores, la socialización paralela entre éstos y el consecuente desarrollo de una eventual identidad regional. Si bien es cierto que aún no puede sostenerse el pleno desarrollo de tales elementos, la relevancia de las instancias antes reseñadas es que han incrementado la confianza, mejorado la preparación profesional e instaurando relaciones personales de mutuo conocimiento entre los actores involucrados. De este modo, estos avances en el terreno bilateral han modificado las percepciones negativas y competitivas hacia percepciones positivas centradas en los beneficios de la cooperación y la integración.

6. Véase URL: <http://www.defensa.cl/noticias_anteriores/2004/0607viaje_haiti.htm>. Revisado en Abril de 2007.

7. Véase URL: <http://www.defensa.cl/noticias_anteriores/2006/llullaillaco.htm>. Revisado en Abril de 2007. 
En consecuencia, en materia de seguridad y defensa las relaciones entre los países del Cono Sur se caracterizan hoy por su transparencia y el progresivo avance de las medidas de confianza. $\mathrm{Si}$ bien la evolución de éstas ha sido dispar, no obstante ello, indiscutiblemente su desarrollo ha alejado cualquier posibilidad de confrontación en el futuro próximo. Ello demuestra un notable adelanto de la certidumbre en las relaciones estratégico-militares entre los países del MERCOSUR, con efectos de derrame para Sudamérica en su conjunto.

Por último, para complementar este sucinto panorama, se debe subrayar que, junto con los aspectos estratégico-militares se han realizado importantes avances en materia de seguridad interior en el contexto del MERCOSUR. La reunión de Ministros del Interior y el Foro de Consulta y Concertación Política han sido protagónicos en tal sentido. En el marco de las reuniones de Ministros del Interior y de sus grupos de trabajo han surgido relevantes avances en la lucha común contra el tráfico organizado de drogas y de armas, contra el terrorismo y otros delitos transnacionales, que se han concretizado, entre otros aspectos, en acuerdos de cooperación policial, en una red de información subregional en materia de seguridad interior y un plan subregional aprobado por la reunión de Ministros (véase Flemes, 2004b). A este respecto, cabe subrayar que ante un escenario crecientemente interdependiente, tales amenazas comunes también han actuado como un catalizador de la cooperación intergubernamental, en el marco de la integración. De la misma forma, estos avances en materia de seguridad interior han servido como un necesario complemento para el desarrollo de la mencionada comunidad de seguridad.

Concretamente, los mayores avances en materia de seguridad interior se han dado a partir de los atentados del 11 de septiembre de 2001, aunque los antecedentes se encuentran en el atentado contra la AMIA, en Buenos Aires, en julio de 1994, a raíz del cual se estableció la celebración de reuniones de los Ministros del Interior del bloque, a partir de diciembre de 1996, con una Secretaría Pro Tempore en cada país anfitrión. Durante la primera reunión de Ministros del Interior del MERCOSUR, que se realizó el 30 de mayo de 1997, en Asunción, se abordaron temas como el terrorismo, el tránsito de bienes y personas y el tráfico de armas. Una especial preocupación recayó en el foco de inseguridad que implicaba la Triple Frontera. Lo anterior llevó a que en la cuarta Reunión de Ministros del Interior efectuada en Brasilia el 20 de noviembre de 1998, se estableciera el Sistema de Información de Seguridad del MERCOSUR (SISME). El SISME corresponde a un instrumento de intercambio de información, que consiste en una plataforma de comunicaciones desarrollada conjuntamente por los países del bloque y sus asociados, con el objeto de cooperar en el procesamiento de datos relacionados con temas policiales, control de armas, personas y vehículos, entre otros ${ }^{8}$.

Por último, cabe destacar que el MERCOSUR fue la primera subregión latinoamericana en crear su propio mecanismo para el control de armas de fuego, después de la Declaración Presidencial

8. Véase URL: <http://www.ssi.gov.cl/n201_28-03-2012.html>. Revisado en Abril de 2013. 
sobre como Combatir la Fabricación y el Tráfico llícito de Armas, Municiones y Materiales Relacionados en el Cono Sur, firmada en abril de 1998. Dicha Declaración establece el Plan de Cooperación y Asistencia Recíproca para la Seguridad Regional, en el cual se abordan diversos aspectos del crimen organizado, incluyendo el tráfico ilegal de armas.

\section{LA RELACIÓN ENTRE EL MERCOSUR Y LA UNASUR}

Como sostienen Flemes y Radseck (2009:18), el MERCOSUR y la UNASUR son las estructuras claves que impactan la gobernanza regional en el ámbito de la seguridad. EI MERCOSUR ampliado, con la entrada de Venezuela como miembro pleno, es geográficamente congruente con UNASUR. Ambas instancias han servido igualmente como un marco para generar posiciones políticas convergentes en la región, tanto en su participación en organismos multilaterales, como en las relaciones con actores extrarregionales, como fue el caso del apoyo que ambas instancias expresaron a Argentina en su reivindicación de las Islas Malvinas.

El origen de la UNASUR se remonta a las Cumbres de Jefes de Estado y Gobierno que, a instancias de Brasil, se comenzaron a desarrollar desde el año 2000, las que decantaron en la Comunidad Sudamericana de Naciones, establecida el año 2004. La misma Comunidad dio lugar a UNASUR luego de la Cumbre de Isla Margarita, celebrada en abril de 2007, siendo su Tratado Constitutivo firmado el 23 de mayo de 2008. Para Brasil, impulsar la UNASUR implicaba dotar de un sentido verdaderamente regional a una integración que primariamente había sido pensada a nivel subregional. Incluso, algunos analistas postulan que, para este país, el MERCOSUR representa un "ensayo" para una integración superior con América del Sur (Saccone, 2008:33). De hecho, como sostiene el profesor Félix Peña (2009), ya desde sus orígenes Brasil percibió al bloque como una instancia de alcance sudamericano. Durante la negociación del Tratado de Asunción, fue el propio Canciller Amorim quien propuso sustituir el nombre de "Mercado Común del Cono Sur", por el de "Mercado Común del Sur" (Peña, 2009:51).

En sus orígenes la UNASUR, que integra y vincula en su seno a países del MERCOSUR y la CAN, fue visualizada como una manera de avanzar en la colaboración para la creación de bienes públicos regionales, que contribuyan a la gobernanza de la región en su conjunto. Esta iniciativa nació con el fin de favorecer el diálogo político y la inserción internacional de la región. Busca promover una mayor integración cultural, social, económica y política, y atenuar las desigualdades, lograr una mayor inclusión social, fortalecer las democracias y reducir las asimetrías, en el marco del fortalecimiento de la soberanía e independencia de los Estados. Asimismo, como una instancia predominantemente política, en la práctica, la UNASUR ha desempeñado un rol de relevancia en la mediación de diversos conflictos internos e interestatales suscitados en la región (Planas, 2010).

En el marco de la UNASUR, el 24 de febrero de 2008 el Presidente Lula y el Ministro de Defensa de Brasil, Nelson Jobim, lanzaron oficialmente la idea de crear un Consejo de Defensa 
Suramericano, durante una visita de Estado a Argentina. En la ocasión, el Ministro Jobim sostuvo que el objetivo del nuevo organismo sería "el entendimiento con todos los países sudamericanos para que pudiesen tener la misma palabra sobre defensa en los organismos internacionales y resolver por medio de este Consejo las eventuales cuestiones sobre defensa que surjan" (en Moreira, 2008:7).

La decisión para establecer el Consejo de Defensa Suramericano se adoptó en diciembre de 2008, con ocasión de la reunión extraordinaria de las Jefas y Jefes de Estado y de Gobierno de UNASUR, celebrada en Salvador de Bahía. El organismo se presenta como una instancia de consulta, cooperación y coordinación en materias de defensa. Además de consolidar a la región como una zona de paz, el Consejo tiene el objetivo de contribuir al fortalecimiento de la unidad regional, generando consensos para fortalecer la cooperación en el ámbito de la defensa, en el contexto del poco constante proceso de integración sudamericano.

El Consejo de Defensa Suramericano fue impulsado por Brasil, en desmedro de la anterior

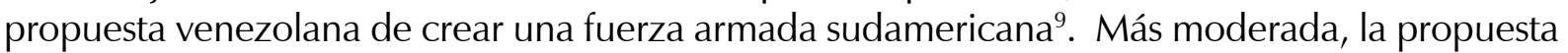
brasileña involucraba la generación de una instancia flexible de consulta, cooperación y coordinación política en el terreno defensivo, antes que de un acabado mecanismo de seguridad colectiva. Asimismo, representa una manera de repensar el sistema estratégico interamericano, propio de la Guerra Fría, y de proyectar a la región los avances expresados por el MERCOSUR en estas materias. Desde sus orígenes, con la creación del Consejo se pretendió contribuir a la prevención de conflictos en la región e impulsar una instancia de diálogo de los Ministerios de Defensa sudamericanos, reduciendo de este modo las desconfianzas, con miras al desarrollo de una eventual política de defensa común.

Bajo la perspectiva de Brasil, impulsar el Consejo otorgaría una mayor legitimidad a su pretensión de ocupar un asiento permanente en el Consejo de Seguridad de Naciones Unidas y permitiría a la región encarar los temas de defensa con una perspectiva regional, dejando a un lado la presencia norteamericana, tan involucrada con el proceso de seguridad colombiano. Como sostiene María Alejandra Saccone:

"El interés nacional brasileño y su proyección como potencia emergente necesitan que América del Sur se afirme como zona de paz, por una parte; pero también, que se preserve de la intervención e injerencia de Estados Unidos" (Saccone, 2008, p. 35).

El impulso del Consejo de Defensa por parte de Brasil debe entenderse en el marco de la prioridad sudamericana asumida por la administración Lula, uniéndose al liderazgo asumido

9. El Presidente Hugo Chávez propuso en 2003 crear la Organización del Atlántico Sur (OTAS), una especie de OTAN sudamericana. 
por este país en la Misión de Estabilización de Naciones Unidas en Haití (MINUSTAH), y como parte de una estrecha vinculación entre su política exterior y de defensa. En 2008, el Presidente brasileño sostenía que "O Brasil quer asociar e seu futuro ao destino da América do Sul. Nehum de nossos países pode, sozinho, aspirar a prosperidade. Mais do que generosos, temos que ser solidários" (en Rizzo de Oliveira, 2009:80). Según destaca Nicolás Comini, al mismo tiempo que Brasil impulsaba el Consejo, paralelamente lanzaba un amplio proceso de reactivación y modernización de su complejo industrial de producción en el ámbito de la defensa, que ya había sido diagramado en el proyecto "Brasil 3 tiempos: 2007, 2015, 2022" y en el Programa de Aceleración del Crecimiento (2007), que fue acompañado por la aprobación de la Estrategia Nacional de Defensa (2008), el Decreto de Reglamentación de la Ley de Movilización Nacional (2008) y la realización de los Ejercicios Frontera Sur, de manera paralela al reclamo brasileño por incrementar su producción de energía nuclear (Comini, 2010:17-18) ${ }^{10}$.

El Consejo de Defensa Suramericano pretende constituirse como un foro dedicado al análisis y diálogo sobre los temas de defensa, con miras a consolidar a América del Sur como una zona de paz y libre de conflictos. El Plan de Acción del Consejo se estructura en torno a cuatro ejes: políticas de defensa; cooperación militar, acciones humanitarias y operaciones de paz; industria y tecnología de la defensa; y formación y capacitación.

En último término, el Consejo de Defensa busca fortalecer una identidad sudamericana en el ámbito de la defensa, constituyéndose como una instancia expresiva de una naciente comunidad de seguridad a nivel regional. Como se indicó más arriba, esta comunidad, de carácter pluralista en los términos planteados por Karl Deutsch, tiene su origen en los avances estratégicos que se registraron en el Cono Sur con el desarrollo del MERCOSUR. Si esta última instancia tuvo como líderes de la integración a Argentina y Brasil, lo cierto es que a nivel sudamericano sólo éste último aparece en un papel prominente. Es decir, teniendo como base la apreciación geopolítica de Brasil respecto de la región, pensada en términos de América del Sur antes que como América Latina (lo que consecuentemente excluye a México del proceso), el liderazgo brasileño -aunque todavía poco constante- aparece como el responsable principal de la proyección sudamericana de la comunidad de seguridad surgida originalmente en el Cono Sur.

De tal manera, los esfuerzos de la UNASUR ligan los del MERCOSUR y la CAN ${ }^{11}$, proyectando a nivel sudamericano la comunidad de seguridad desarrollada originalmente a nivel subregional. Desde la perspectiva de este trabajo, el MERCOSUR ha servido como núcleo duro de la

10. Específicamente, la nueva Estrategia Nacional de Defensa plantea la ampliación, modernización y reposición de las fuerzas militares, además de referirse a la industria de la defensa. La estrategia, entre otras directrices, se propone estimular la integración sudamericana, no solo para contribuir a la defensa de Brasil, sino también para fomentar la cooperación militar regional y la integración de las bases industriales de defensa.

11. Respecto de la subregión andina, se debe señalar que, en julio de 2004, se suscribió la Declaración de San Francisco de Quito sobre el Establecimiento y Desarrollo de la Zona de Paz Andina. 
integración defensiva a nivel sudamericano. Por tanto, siguiendo a María Alejandra Saccone, puede concluirse que:

“EI MERCOSUR y la UNASUR pueden constituir un tándem perfecto con la condición del reconocimiento de las limitaciones y la definición de objetivos políticos al modelo europeo de los 50, a fin de no limitar las acciones a cuestiones de seguridad meramente protectivas y lograr definitivamente un camino de desarrollo autosustentable, teniendo presente que este tema también es una cuestión de seguridad" (Saccone, 2008:36).

Como se aprecia, ambas instancias se constituyen como las iniciativas de mayor relevancia al momento de dotar de institucionalidad al espacio sudamericano en el terreno estratégico, siendo el rol de Brasil un factor clave de ambos procesos. Por tal motivo, MERCOSUR y UNASUR deben complementarse, de manera de contribuir a la paz y la estabilidad política de la región (Peña, 2009, 2012). Los últimos sucesos acontecidos en Paraguay demuestran la necesidad de incrementar el trabajo conjunto de los países en tal sentido.

\section{CONCLUSIONES}

Como se ha sostenido en este trabajo, el escenario internacional actual se caracteriza por la creciente tendencia a la configuración de un multipolarismo, marcado por la fragmentación y la descentralización del poder mundial. Estos atributos definen una política internacional radicalmente diferente a la que contextualizó el establecimiento del MERCSOUR en los albores de la década del noventa, marcada por el fin de la Guerra Fría y la transitoria unipolaridad estadounidense. El escenario crecientemente multipolar que se aprecia en la política mundial del presente se manifiesta en el cada vez mayor protagonismo de las regiones y en la disposición de nuevos polos de poder. En consecuencia, la relevancia de América del Sur en el mundo dependerá de la calidad de las relaciones de los países que la componen y de las estrategias que asuman en su inserción internacional. Desde luego, el éxito o fracaso de este intento, así como su capacidad de incidir en las cuestiones mundiales, estribará en la capacidad de los actores para actuar de manera coordinada, sobre la base de intereses y objetivos comunes. Bajo la perspectiva de este autor, la integración es una condición sine qua non de la inserción internacional de los países y de la región como un todo.

En este marco, reflexionar sobre las tendencias que se observan en el MERCOSUR, el proceso de integración que se puede apreciar, hasta el momento, como relativamente más exitoso en Sudamérica, se constituye como una cuestión fundamental para avizorar las potencialidades de la región en el contexto internacional. Como se indicó anteriormente, el MERCOSUR ha estado sometido a profundas críticas, vinculadas, entre otros, con los cuestionamientos por parte de los socios menores acerca de las verdaderas posibilidades de que el bloque responda adecuadamente a sus intereses y expectativas. De todos modos, en este breve artículo se ha pretendido 
desarrollar la idea de que las críticas al MERCOSUR tienen un carácter metodológico y no existencial. Es decir, apuntan a que el bloque trabaje mejor, valorando las posibilidades y la necesidad de avanzar por el camino de la integración.

Por lo demás, las dificultades del MERCOSUR se vinculan con los tropiezos que debe enfrentar la integración regional en su conjunto, caracterizada, hasta el momento, por la carencia de un liderazgo definido, la vigencia de los nacionalismos y la retórica de las autoridades, que no van de la mano de acciones concretas por profundizar la integración. Discursos altisonantes y concreciones modestas han generado distorsiones entre los resultados y expectativas sobre la integración, lo que ha incidido de manera decisiva en las críticas acerca de la integración real. Pese a ello, cabe subrayar que la integración, por definición, no es un proceso lineal, siendo siempre un proceso en construcción. Sus posibilidades en el futuro dependerán de la voluntad política de los países y sus gobiernos.

Sin embargo, como es posible apreciar, pese a las críticas al MERCOSUR y las vicisitudes que ha debido enfrentar en el terreno económico y comercial, lo cierto es que en el terreno estratégico el bloque ha sido particularmente exitoso, dotando al Cono Sur de paz y estabilidad, siendo esta esfera una de las potencialidades principales que se pueden distinguir. El MERCOSUR ha servido como marco general para el acercamiento y cooperación entre los países, principalmente entre Argentina y Brasil. De tal modo, en el Cono Sur las políticas de enfrentamiento y competencia por el liderazgo militar y las tensiones limítrofes han sido desplazadas por una tendencia creciente hacia la cooperación, lo que se ha expresado, entre otros elementos, en confianza interestatal y en una dinámica cooperación militar. Más allá de las dificultades y críticas sobre su perfomance económica, lo cierto es que el MERCOSUR ha contribuido de manera fundamental al mantenimiento de la paz en el Cono Sur, constituyéndose en un marco adecuado para un proceso de convergencia en los planos de la seguridad y la defensa, con efectos de derrame a nivel sudamericano.

La institucionalización de la cooperación del ámbito político y estratégico en el MERCOSUR tuvo un momento clave hacia mediados de 1998, con la institución de la denominada cláusula democrática y, desde luego, con la Declaración Política del MERCOSUR, Bolivia y Chile como Zona de Paz, de julio de ese año. En virtud de tales avances, los países que participan del MERCOSUR, como miembros plenos o asociados, mantienen en la actualidad políticas de defensa mutuamente cooperativas y ponen en marcha una activa cooperación militar, que se ha concretado en conferencias, reuniones, ejercicios conjuntos, cooperación técnica y programas de intercambio entre las respectivas academias.

De este modo, con algunos obstáculos -como la escasa institucionalización de la integración- se ha avanzado progresivamente en la conformación de una comunidad pluralista de seguridad en el Cono Sur, donde los Estados solucionan sus conflictos por otros instrumentos políticos, como el diálogo diplomático, antes que a través de la guerra y la coerción. Un aspecto relevante en tal sentido, es que tales progresos han tendido a derramarse a nivel sudamericano, donde se 
aprecian importantes avances con la creciente consolidación de la UNASUR y, en su marco, del Consejo de Defensa Suramericano. En tales circunstancias, es posible sostener que, teniendo un origen subregional en el Cono Sur, con el MERCOSUR como núcleo duro, actualmente se aprecia la proyección de una comunidad de seguridad naciente a nivel de América del Sur.

En Sudamérica, el MERCOSUR y la UNASUR se constituyen como las estructuras claves de la gobernanza regional en el ámbito estratégico. Ambas instancias deben complementarse, de manera de contribuir a la paz y la estabilidad política de la región, donde resalta el recientemente constituido Consejo de Defensa Suramericano. La creación del Consejo fue impulsada por Brasil con miras a incrementar la estabilidad, consolidar una zona de paz y, en último término, favorecer una identidad regional en el ámbito de la defensa. Bajo la perspectiva del coloso sudamericano, impulsar el Consejo favorecería su prestigio internacional y liderazgo y, en consecuencia, le otorgaría una mayor legitimidad a su pretensión de ocupar un asiento permanente en el Consejo de Seguridad de Naciones Unidas. Tanto en el MERCOSUR como en la UNASUR, el comportamiento de Brasil será decisivo.

Teniendo como base todo lo anterior, durante el desarrollo de este trabajo se ha pretendido reforzar la idea de que, considerando que la región se ha vuelto crecientemente interconectada e interdependiente, tanto desde el prisma económico-comercial, como desde el político-estratégico, es posible apreciar que la integración en América del Sur ha favorecido la neutralización de los tradicionales conflictos interestatales, una paulatina tendencia hacia la superación de la fragmentación y la consecuente estabilización del "vecindario". De este modo, la paz y la seguridad en la región se han constituido al presente como uno de los grandes activos de la integración y como una condición fundamental para avanzar por la senda del desarrollo, de manera que asegure una adecuada inserción internacional de América del Sur en su conjunto, siendo los avances que se aprecian en el MERCOSUR y la UNASUR altamente valiosos a este respecto.

\section{REFERENCIAS}

- $\quad$ Adler, E. (2001). The change of change: Peaceful transitions of power in the multilateral age. En C. Kupchan, E. Adler, J. Coicaud \& Y. Foong Khong (Eds), Power in Transition. The peaceful change of international order. Tokyo: United Nations University Press.

- Bergsten, F. (1996). Globalizing free trade: the ascent of regionalism. Foreign Affairs. Mayojunio.

- $\quad$ Buzan, B. \& Wæver, O. (2003). Regions and Powers. The Structure of International Security. Cambridge: Cambridge University Press.

- Comini, N. (2010). El rol del Consejo de Defensa de la UNASUR en los últimos conflictos regionales. Nueva Sociedad. 
- Deutsch, K. (1974). El análisis de las relaciones internacionales. Buenos Aires: Paidós.

- $\quad$ Diamint, R. (1999). Integración y seguridad. La dialéctica de los actores argentinos. En F. Rojas (ed.). Argentina, Brasil y Chile: integración y Seguridad. Caracas: Flacso-Chile/Editorial Nueva Sociedad.

- Donadio, M. (2000). Las opciones de seguridad estratégica para los países del Cono Sur. Fuerzas Armadas y Sociedad,

- Garay, C. (2003). Las políticas de defensa nacional en el Mercosur y asociados. Historia, procesos, tendencias 1990-2000. Santiago: Universidad de Santiago de Chile.

- Gaspar, G. (2003). Desafíos y dilemas de seguridad en América Latina en la post Guerra Fría. Estudios Internacionales,

- Girault, C. (2009). El aspecto geopolítico de la Integración Regional. Estudios Internacionales, XLII, 163. pp. 83-100.

- Ghitis, F. (2006). South American divisions hinder dream of unity. World Politics Review. Diciembre. Recuperado en abril de 2013 de http://www.worldpoliticsreview.com/articles/ 421/south-american-divisions-hinder-dream-of-unity>

- Griffiths, J. (2006). La cooperación en el plano de la defensa. Una visión desde la perspectiva de Chile, en el ámbito vecinal. En F. Kernic, \& T. Chuaqui (Eds). Seguridad y cooperación: aspectos de la seguridad y las relaciones entre la Unión Europea y América Latina. Viena: Schriften der Landesverteidigungsakademie.

- $\quad$ Flemes, D. (2004a). Institution building in MERCOSUL's defence- and security sector (I). Brazil's defence cooperation: between dominant armed services and marked bilateralism. Arbeitspapiere des IKK, 20.

- $\quad$ Flemes, D. (2004b). Institution building in MERCOSUL's defence- and security sector (II). The common containment of transnational security threats. Arbeitspapiere des IKK, 22.

- $\quad$ Flemes, D. \& Radseck, M. (2009). Creating multilevel security governance in South America. GIGA Working Papers, 117.

- Kacowicz, A. (2008). Latin America and the world: globalization, regionalization, and fragmentation. Nueva Sociedad,

- Kupchan, C. (2010). How enemies become friends. The sources of stable peace. Princeton and Oxford: Princeton University Press. 
- $\quad$ Lorenzo, N. (2006). Situación actual y perspectivas del MERCOSUR. Madrid: Fundación CILAE.

- Magariños, G. (2000). Integración multinacional. Teoría y sistemas. Montevideo: ALADIUniversidad ORT.

- $\quad$ Malamud, C. (2009). La crisis de la integración se juega en casa. Nueva Sociedad, 219.

- Merke, F. (2012). Brasil, política exterior y programa nuclear. En K. DerGhougassian (coord.). La defensa en el siglo XXI. Argentina y la seguridad regional. Buenos Aires: Capital Intelectual.

- Molina, C. (2000). Cooperación regional: potencialidades y limitaciones desde la perspectiva de la defensa nacional. Fuerzas Armadas y Sociedad, 15, 2.

- $\quad$ Moreira, Á. (2008). Consejo Sudamericano de Defensa: Hacia una integración regional en defensa. RESDAL.

- $\quad$ Peña, F. (2008). Relaçoes Brasil/Argentina. Política Externa, 16, 4.

- $\quad$ Peña, F. (2009). Integración del espacio sudamericano. ¿La UNASUR y el MERCOSUR pueden complementarse? Nueva Sociedad,

- Peña, F. (2012). MERCOSUR as a regional and global protagonist. RSCAS Policy Papers, 2012/01.

- $\quad$ Pey, C. \& Riquelme, J. (2007). Algunos alcances políticos y jurídicos del MERCOSUR desde una perspectiva chilena. Revista Austral de Ciencias Sociales,

- $\quad$ Planas, R. (2010). UNASUR finds a role in conflict mediation. World Politics Review. Octubre. Recuperado en abril de 2013 de http://www.worldpoliticsreview.com/articles/6623/ unasur-finds-a-role-in-conflict-mediation $>$

- $\quad$ Pinheiro, S. (2012). The future of MERCOSUR. Austral: Brazilian Journal of Strategy \& International Relations, 1, 1.

- Rizzo de Oliveira, E. (2009). A Estrategia Nacional de Defesa e a reorganiza“ão e transforma"ão das for"as armadas. Interesse Nacional. Abril-junio.

- $\quad$ Robledo, M. \& Rojas, F. (2002). Construyendo un régimen cooperativo de seguridad en el Cono Sur de América Latina. Elementos conceptuales, políticos y estratégicos. Fuerzas Armadas y Sociedad, 17, 1-2. 
- Rojas, F. (2002). Espacios para el diálogo. El fin de la guerra fría y la solución de conflictos en el Cono Sur. Desarrollo y Cooperación, 5. Recuperado en mayo de 2007 de http.www.seguridadregional-fes.org/upload/3080-001_g.pdf: >

- Rosenthal, G. (1993). Treinta años de integración en América Latina: un examen crítico. Estudios Internacionales, 101.

- $\quad$ Saccone, M. (2008). UNASUR: visiones desde el MERCOSUR. Revista de la Integración, 2.

- $\quad$ Serbin, A. (2009). América del Sur en un mundo multipolar: ¿es la UNASUR la alternativa? Nueva Sociedad, 219.

- $\quad$ Silva, M. (2011). La Alianza Bolivariana para las Américas (ALBA): Aspectos de seguridad y defensa y elementos de participación social. En A. Serbin (Coord.), De la ONU al ALBA: Prevención de conflictos y espacios de participación ciudadana. Buenos Aires: Ediciones CRIES.

- Yopo, M. (2009). Nuevos escenarios en la defensa y la seguridad regional: el Consejo de Defensa Sudamericano de UNASUR. Análisis y Propuestas.

- Zakaria, F. (2009). The Post-American World. New York: W.W. Norton \& Company.

\section{Fuentes electrónicas}

- $\quad$ http://www.ultimasnoticias.com.uy/hemeroteca/270709/prints/act06.html. Recuperado en junio de 2012

- $\quad$ http://www.nuso.org/upload/articulos/Apuntesdeintegracion6.pdf $>$. Recuperado en junio de 2012

- $\quad$ http://www.infodefensa.com/?noticia=argentina-y-brasil-profundizan-sus-lazos-en-materiade-defensa. Recuperado en junio de 2012

- $\quad$ http://www.infodefensa.com/?noticia = argentina-y-brasil-profundizan-agenda-bilateral-enmateria-de-defensa $>$. recuperado en junio de 2012

- http://www.defensa.cl/noticias_anteriores/2004/0607viaje_haiti.htm>. Recuperado en abril de 2007

- $\quad$ http://www.defensa.cl/noticias_anteriores/2006/llullaillaco.htm >. Recuperado en abril de 2007

- $\quad$ http://www.ssi.gov.cl/n201_28-03-2012.html>. Recuperado en abril de 2013 